\title{
BMJ Open Association between livelihood capital and catastrophic health expenditure among patients with critical illness: a cross-sectional study in rural Shandong, China
}

Xin Che (D) , ${ }^{1}$ Jiajia Li, ${ }^{1,2}$ Wenhao Fu, ${ }^{1,2}$ Feng Fang ${ }^{1}$

To cite: Che X, Li J, Fu W, et al. Association between livelihood capital and catastrophic health expenditure among patients with critical illness: a cross-sectional study in rural Shandong, China. BMJ Open 2021;11:e051234. doi:10.1136/ bmjopen-2021-051234

- Prepublication history and additional supplemental material for this paper are available online. To view these files, please visit the journal online (http://dx.doi.org/10.1136/ bmjopen-2021-051234)

Received 23 March 2021 Accepted 13 October 2021

D) Check for updates

(c) Author(s) (or their employer(s)) 2021. Re-use permitted under CC BY-NC. No commercial re-use. See rights and permissions. Published by BMJ.

${ }^{1}$ Center for Health Management and Policy Research, School of Public Health, Cheeloo College of Medicine, Shandong University, Jinan, China ${ }^{2} \mathrm{NHC}$ Key Lab of Health Economics and Policy Research,Shandong University, Jinan, China

Correspondence to Ms Jiajia Li; lijiajia@sdu.edu.cn

\section{ABSTRACT}

Objective The objective of this study is to examine the association between livelihood capital and catastrophic health expenditure (CHE).

Design Between July and August 2019, a cross-sectional study was conducted in critically ill patients.

Setting Shandong, China.

Participants 1041 households with critically ill patients from 77 villages.

Primary and secondary outcome measures We defined expenditure as being catastrophic if a household's outof-pocket payments were greater than or equal to $40 \%$ of their capacity to pay. Using the sustainable livelihoods framework, this study explored the associations between CHE and the various forms of livelihood capital-inclusive of human capital, natural capital, physical capital, financial capital and social capital. $\chi^{2}$ tests, t-tests, Wilcoxon tests and binary logistic regression analysis were performed to examine these associations.

Results The incidence of CHE among households with critically ill patients was $76.37 \%$ in this study. Better livelihood capital was significantly associated with lower incidence of CHE. After controlling for confounding factors, households with healthier patients (OR 0.47, 95\% Cl 0.23 to 0.96 ), more real estate ownership (OR $0.35,95 \% \mathrm{Cl}$ 0.19 to 0.67 ) and better economic status (OR $0.33,95 \%$ $\mathrm{Cl} 0.18$ to 0.62 ) were associated with a reduction in the occurrence of $\mathrm{CHE}$.

Conclusions Livelihood capital was significantly associated with CHE in rural families with critically ill patients. This association suggests that, in addition to providing health insurance to the critically ill, more attention should be paid to their ability to create and preserve livelihood capital.

\section{BACKGROUND}

Illness-related poverty is a major challenge in rural China. In 2016, 42.6\% of Chinese rural poor attributed their poverty chiefly to illness. ${ }^{1}$ The causes of poverty are internal and external. The external cause is the negative impact of diseases and disasters, while the internal cause is low risk tolerance deriving
Strengths and limitations of this study

- To our knowledge, this study is the first to systematically examine the association between livelihood capital and catastrophic health expenditure among critically ill patients.

- All participants were from rural China, a relatively vulnerable population.

- Robust SE regression and logarithmic treatment of some of the variables were used to reduce the heteroscedasticity bias.

- Causal relationship is difficult to determine in a cross-sectional study.

from insufficient accumulation of livelihood assets. Critical illnesses are the most common external cause of poverty, and are characterised by their long duration, complex treatments and high cost. ${ }^{2}{ }^{3}$ The considerable out-of-pocket (OOP) payments caused by such illnesses not only inflict significant economic harm on patients, but also limit livelihood capital accumulation for patients' families. In some instances, for example, critical illnesses may lead to patients being fired from their jobs. ${ }^{45}$ The ensuing loss of income sources may force households to choose between satisfying basic needs like education and purchasing medical services, ${ }^{67}$ thus interfering with human capital accumulation. ${ }^{8}$ In general, critical illnesses cause both immediate hardship and longer-lasting poverty. ${ }^{9}$ Poverty, in turn, is correlated with poor health, creating a vicious cycle. ${ }^{10}$

In 2016, critical illnesses led to an estimated 36.19 million deaths worldwide. ${ }^{11}$ Cancer is a particularly widespread example of critical illness, with an estimated 18.1 million diagnoses and 9.6 million cancer-related deaths in 2018. ${ }^{12}$ In China, cancer is associated with $23.91 \%$ of deaths every year, as well as 
over 220 billion dollars in annual medical expenses. ${ }^{13}$ Cancer survivors, in turn, tend to have higher ongoing OOP costs. ${ }^{14-16}$ In general, critically ill patients experience financial difficulties, ${ }^{6}{ }^{17}$ and are at high risk of catastrophic health expenditures (CHE).

Livelihood capital refers to the capabilities, material and social resources, and activities that an individual or household needs in order to survive, to mitigate risks or shocks and to thrive. ${ }^{18}$ Livelihood capital can help rural households cope with risk and maximise development potential. ${ }^{19}{ }^{20}$ One risk that livelihood capital can mitigate is CHE. Studies ${ }^{21-23}$ have found that many forms of human capital-including educational level and health status-can affect CHE. Economic status, which represents a household's financial capital, was also found to influence CHE. ${ }^{24}{ }^{25}$ Moreover, some studies have highlighted the perceived benefit of increased social capital for rural. ${ }^{26}$ Can livelihood capital reduce the vulnerability of rural families to disease risk? Although the Sustainable Livelihoods Framework proposed by Department for International Development (DFID) can be applied as a flexible tool to improve household resilience, few studies examine the role of livelihood capital as a unifying framework for dealing with the risk of critical illness.

Therefore, the aim of this study is to examine whether livelihood capital is associated with CHE occurrence as well as the role of livelihood capital among critically ill patients. In particular, this study pays special attention to rural residents because they are more vulnerable to critical diseases than their urban counterparts. In 2015, for example, cancer incidence was not only higher in rural China than urban China, but the diagnosis was often at a later stage. ${ }^{27}$ Studies ${ }^{2125} 28$ found that rural household is more likely to incur CHEs due to a lack of sufficient money for treatment in comparison to urban households. In addition, without regular wage income, rural residents are more dependent on livelihood capital such as land, production tools and social networks. ${ }^{29}$ An examination of the relationship between livelihood capital and CHE may improve outcomes for critically ill patients in rural China.

\section{METHODS}

\section{Study setting}

An explorative cross-sectional study was conducted between July 2019 and August 2019 in Shandong Province, an agricultural province with a 2019 population of over 100 million. ${ }^{30}$ As is the case in China generally, Shandong's wealth and medical resources are unevenly distributed, particularly since approximately half of its population lives in rural areas. Notably, Shandong was one of the first provinces to implement a universal Critical Illness Insurance (CII), which sought to extend basic Chinese health insurance to protect all provincial citizens from high medical expenses. All Shandong residents are covered by the same CII policy regardless of where they live within the province. By contrast, most other regions of China have CII insurance that varies by city and even by county. Given Shandong's favourable health insurance environment, it is particularly important to determine whether rural residents of Shandong rely on livelihood capital when facing critical illnesses. This study, therefore, drew its sample patient population from rural Shandong.

All participants provided informed written consent to participation in this study prior to the start of study activities.

\section{Inclusion criteria for critical illnesses}

We used the following two inclusion criteria for critical illnesses in our research:

1. Critical illnesses were defined as diseases with OOP compliance expenses which exceeded the local CII reimbursement threshold under Shandong Province's 2019 CII policy.

2. If OOP compliance expenses did not exceed the local CII reimbursement threshold, critical illness was also defined as any disease with a treatment cycle exceeding 2 years, a low cure rate and significant cumulative medical expenses. Such critical illnesses include sequela of stroke, complications from haematopoietic stem cell transplantation and end-stage renal disease.

CII offers additional reimbursement for individuals insured through basic Chinese health insurance. ${ }^{31} \mathrm{CII}$ is applicable when an enrollee's OOP expenses exceed a certain threshold after basic social health insurance reimbursement. Like the basic Chinese health insurance, CII covers only a subset of medicines, consumables and treatments. Our inclusion criteria were, therefore, broader than CII's coverage criteria.

\section{Sample size}

The sample size was calculated using the following formula: ${ }^{32}$

$$
n=\frac{Z_{1-\alpha / 2}^{2} \times p(1-p)}{\delta^{2}} \times \text { Deff }
$$

Where permissible error: $\delta=0.05$, significance level: $\alpha=0.05$, and design effect coefficient: Deff $=3$. A design effect (Deff) is an adjustment made to find a survey sample size that accommodates larger sample sizes (or wider CIs) than would be expected from a simple random sampling. In general, for a well-designed study, the design effect usually ranges from 1 to $3{ }^{33}$ We take the maximum design effect of 3 . We assume that the $\mathrm{p}=0.5^{33}$ because the rate of patients with critical illness is unknown in the full population. The calculated sample size was 1152 .

\section{Sampling strategy and data collection}

In this study, multistage stratified cluster random sampling was used based on the following administrative hierarchy: 1. In the first stage, we randomly selected three cities: Heze in western Shandong with a CII threshold of $¥ 9500$, Weifang in central Shandong with CII threshold of $¥ 12000$ and Yantai in eastern Shandong with CII threshold of $¥ 16000$. These cities were chosen following an analysis of their social and economic 
development, medical resources, demography and geographical locations.

2. Districts with comparable medical resources were selected in each city. One town was then randomly selected from each district.

3. Qualified respondents were initially screened by village doctors using our inclusion criteria. A subset of these were randomly selected using a computer-generated random number table. The population of each village in China varies greatly, so the corresponding sample size was proportional to the town populations.

A total of 1138 households from 77 villages were recruited in this study. Questionnaires provided in faceto-face interviews recorded patients' health conditions, medical expenses, as well as demographic information for all family members, and household's livelihood capital. It took about 1.5-2 hours for each family to complete all questionnaires of data collection. The definition of family members is defined as follows: (1) Head of household and his/her spouse; (2) Offspring in one household registration or live together; (3) Offspring who live apart but not financially independent, including students, soldiers, people who have worked outside and left home for less than 6 months.

We defined the valid questionnaires as households with living patients and without missing data. Finally, 1041 valid questionnaires were recruited in the statistical analysis.

\section{CHE experience}

Our dependent variable was whether the household occurred CHE in 2018. Commonly used to measure the financial risk of diseases, CHE often involves OOP expenditures that force patients and their families to reduce essential expenditures such as food, housing or children's education. ${ }^{10}$ However, there is no consensus on the denominators and the choice of threshold proportion of household expenditure varies widely. ${ }^{2122} 34$ This study adopts a household's capacity to pay (CTP) as its denominator and uses the WHO's expenditure threshold of $40 \% .^{35}$ A household's CTP is refers to its effective income after basic subsistence needs are satisfied. In this study, the CTP is calculated by subtracting the food expenditure from the household income. OOP expenditure (both direct and indirect) was then calculated for hospitalisations, outpatient services, emergency services and prescription drugs. OOP and CTP both require data of a full year, so in this survey respondents were asked to recall information for the whole year of 2018.

If OOP expenditure divided by CTP exceeded $40 \%$ or when income was insufficient to cover food expenditures $\left(\mathrm{CTP}_{i}<0\right)$ a household was considered to be experiencing CHE. $\mathrm{CHE}_{i}$ is used to indicate whether a household has CHE. The formula is as follows:

$$
C H E_{i}=\left\{\begin{array}{l}
1, \text { if } \frac{O O P_{i}}{C T P_{i}} \geq 40 \% \\
0, \text { if } \frac{O O P_{i}}{C T P_{i}}<40 \%
\end{array}\right.
$$

$O O P_{i}$ represents the OOP of the 'i-th' family; $C T P_{i}$ represents the capacity of the 'i-th' family to pay.

\section{Theoretical framework}

The Sustainable Livelihoods Framework developed by DFID illustrates how rural households leverage social and economic resources to survive and thrive. ${ }^{18}$ The framework consists of five components, shown in figure 1: vulnerability context, livelihood capital, transforming structure and processes, livelihood strategies and livelihood outcomes. These components are interconnected in several ways and merit closer examination.

Being sick is often seen as vulnerability context. For critically ill patients, disease impacts the options that are open to them in pursuit of beneficial livelihood outcomes by forcing patients to pay medical expenses. Vulnerability context can be influenced through transforming structures and processes such as insurance policy changes, economic development and institutional responsiveness to patients.

Livelihood capital is the core component of the sustainability livelihoods framework and consists of five types of livelihood capital: natural capital $(\mathrm{N})$, physical capital $(\mathrm{P})$, financial capital $(\mathrm{F})$, social capital $(\mathrm{S})$ and human capital (H). Increasing access to these forms of capital is a primary concern for DFID in its fight against poverty. These five types of capital are independent of each other, but in a sense, they are also interchangeable. Those rich in livelihood capital tend to have a greater range of options and the ability to switch between multiple livelihood strategies. Patients with critical illnesses may nurture and combine their livelihood capital in creative ways to assure

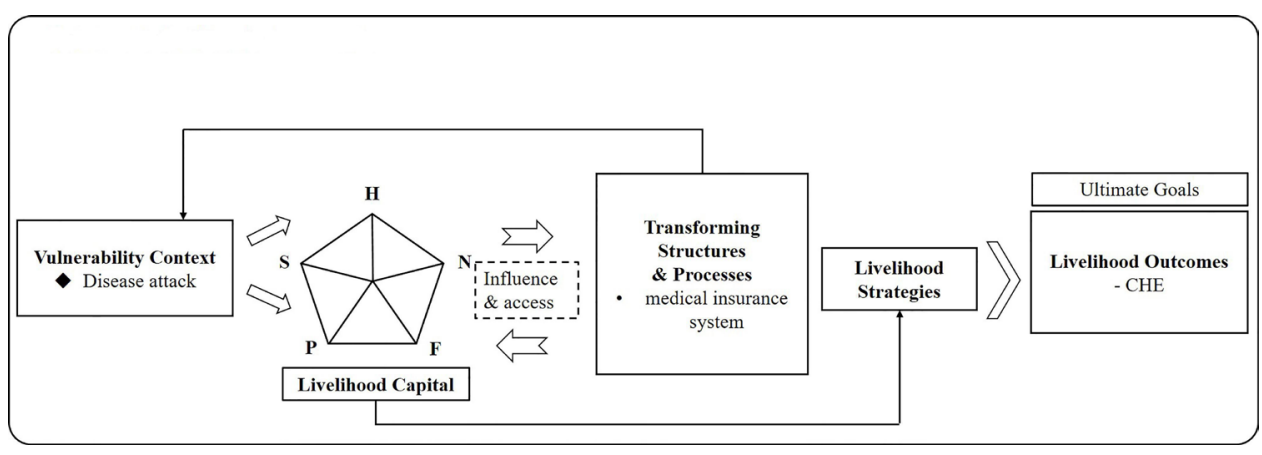

Figure 1 Sustainable Livelihoods Framework. CHE, catastrophic health expenditure. 
Table 1 Index settings and description of livelihood capital

\begin{tabular}{|c|c|c|}
\hline Capital assets & Specific measurement index & Index implications and assignment \\
\hline \multirow[t]{3}{*}{ Control variables } & Gender & $1=$ male, $2=$ female \\
\hline & Marital status & $1=$ married, $2=$ =else (unmarried, divorced, widowed) \\
\hline & Living conditions & $\begin{array}{l}1=\text { live alone/empty nest } \\
2=\text { else }\end{array}$ \\
\hline \multirow[t]{3}{*}{ Human capital } & Education year (householder) & The householder's educational attainment (years) \\
\hline & Education year (patient) & The patient's educational attainment (years) \\
\hline & Health condition (patient) & $\begin{array}{l}\text { The score of EQ-5D* (scores) } \\
\text { The calculation method is shown in the published papers. }{ }^{55}\end{array}$ \\
\hline \multirow{2}{*}{ Physical capital } & Amount of real estate & The number of real estate owned by a family \\
\hline & Household-owned assets & $\begin{array}{l}\text { The number of material assets owned by the household divided by } 12 \text { (total } \\
\text { number). } \\
\text { eg, If a household has a refrigerator and a television set, the index value of } \\
\text { the material assets of the household is } 2 / 12 \text {, that is, } 0.167 \text {. }\end{array}$ \\
\hline Financial capital & Household economic status & $\begin{array}{l}\text { Self-assessment of economic status. } \\
1=\text { wealthy, } 2=\text { middle class, } 3=\text { poor }\end{array}$ \\
\hline \multirow[t]{2}{*}{ Social capital } & Number of constant contacts & $\begin{array}{l}\text { Number of people who have kept in touch with in addition to work or } \\
\text { business needs through the past month }\end{array}$ \\
\hline & Borrowing capability & $\begin{array}{l}1=\text { Not required (able to use deposit) } \\
2=\text { Capable (can be raised through the help of others) } \\
3=\text { Uncertainly (uncertainty about the ability to raise) } \\
4=\text { Incapable (can't raise money at all) }\end{array}$ \\
\hline
\end{tabular}

*We conducted the reliability test using SPSS V.25.0 with a KMO coefficient of 0.798 and a Bartlett's sphericity test of significantly $<0.05$, which concluded that the questionnaire had good structural validity. The Cronbach coefficient of 0.872 was considered good reliability of the questionnaire.

†mu, a unit of area ( $=0.0667$ hectares).

EQ-5D, EuroQol Five Dimensions Questionnaire; HZ, Heze; WF, Weifang; YT, Yantai.

better livelihood outcomes, including physical and financial survival from critical illness.

Transforming structures and processes have a profound influence on access to livelihood capital. For instance, a government can promote human capital by improving health facilities and can protect financial capital through health insurance system reform. In practice, however, the shortcomings of the policies themselves, as well as some obstacles in their implementation, have made them far less effective than expected for the livelihoods of farmers.

In general, the Sustainable Livelihoods Framework demonstrates the relationships and interactions between the components of livelihoods. Livelihood capital is seriously constrained in a context of vulnerability. Meanwhile, external structural and procedural shifts also influence livelihood strategies, which in turn influence livelihood outcomes. Conversely, livelihood outcomes can also influence livelihood capital, creating a new cycle.
Table 1 illustrates this framework and describes the forms of livelihood capital. Control variables such as gender, marital status, dependency ratio, living conditions, survey area and reimbursement rate were also integrated into this model. Here, we use the reimbursement rate to comprehensively reflect the financial protection of health insurance, because the health insurance payment in China is a combination of deductible, limitations and copayment.

\section{Patient and public involvement}

Patients and the public were not involved in the development of the research question or in the design of the study. Patients were informed orally and in writing about the study, but were not involved in recruitment or analysis. There are no plans to disseminate the results directly to study participants.

\section{Data analysis}

Categorical variables are presented as frequencies and percentages. Continuous variables are presented as 
mean \pm SD or median with IQRs, based on normality testing using the Shapiro-Wilk tests. T-tests, Wilcoxon tests and $\chi^{2}$ analyses were used to compare the CHE incidence across households of different livelihood capital levels. Binary logistic regression analysis was performed to identify the association between livelihood capital and CHE after controlling for confounding factors. Robust SE regression was used in addition to logarithmic treatment of some of the variables to reduce the heteroscedasticity bias. A two-tailed $\mathrm{p}<0.05$ was considered statistically significant. All data were analysed with STATA (V.15.0, SE).

To assess livelihood capital's possible endogeneity, we conducted ivprobit regression using whether to draw on savings or loans when critically ill as instrumental variables for financial capital and using reimbursement times as instrumental variable for reimbursement rate. Households that did not sell productive assets to cover medical expenses were screened to control the endogeneity of livelihood capital. Wald tests results (which have $\mathrm{p}$ values of 0.0976 and 0.6018 as shown in online supplemental appendix) do not support the hypotheses that financial capital and reimbursement rate are endogenous variables, supporting the current regression results.

\section{RESULTS}

\section{Descriptive results}

At the $40 \%$ threshold, the overall CHE incidence is $76.37 \%$. A total of 1041 respondents were included in this study, with a mean age of 62.75 years. The majority of the respondents were female $(51.87 \%)$, married $(85.98 \%)$ and living alone/empty-nesters (59.85\%). The average dependency ratio was 0.53 and the mean reimbursement rate was $25.26 \%$. There are $16(1.54 \%)$ households whose CTP is less than $0.576(55.33 \%)$ patients had suffered from critical illnesses for more than 2 years; their average illness length was 3.19 years.

Table 2 compares households with and without CHE. In the univariate analysis, CHE varied across marital status $(p=0.016)$, dependency ratio $(p<0.001)$, living conditions $(p<0.001)$ and reimbursement rate $(p<0.001)$. Households with CHE were associated with less education years of household heads $(p<0.001)$, less education years of patients $(p<0.001)$, worse health conditions of patients $(\mathrm{p}<0.001)$, smaller agricultural acreage $(\mathrm{p}<0.001)$, smaller housing floor area $(\mathrm{p}<0.001)$, less real estate $(p<0.001)$, less household assets $(p<0.001)$, worse household economic status $(\mathrm{p}<0.001)$, less constant contacts $(\mathrm{p}<0.001)$ and worse borrowing capacity $(\mathrm{p}<0.001)$.

\section{Multivariate regression analysis}

Binary logistic regression yielded a wide range of determinants linked with CHE (table 3).

After controlling the confounding factors, all forms of livelihood capital showed significant associations with CHE, except for natural capital and social capital. Improved patient health as reflected in higher EuroQol Five imensions questionnaire (EQ-5D) scores was associated with reduced
CHE (OR 0.47, 95\% CI 0.23 to 0.96). Increased property ownership was likewise associated with reduced CHE (OR $0.35,95 \%$ CI 0.19 to 0.67$)$. Based on our findings for wealthy households (OR $0.33,95 \%$ CI 0.18 to 0.62 ) and middle class households (OR $0.64,95 \%$ CI 0.43 to 0.97 ), wealth was inversely correlated with CHE. Other aspects of livelihood capital such as home size, household-owned assets and a patient's number of constant contacts all lacked statistical significance $(\mathrm{p}>0.05)$.

With respect to control variables, CHE was found to be associated with an increasing dependency ratio (OR $1.66,95 \%$ CI 1.02 to 2.70$)$ and an increasing reimbursement rate (OR $1.93,95 \%$ CI 1.72 to 2.15 ). Critically ill patients living with others were inversely associated with CHE occurrence when compared with those living alone or empty nesters (OR $0.22,95 \%$ CI 0.15 to 0.34 ).

\section{DISCUSSION}

The incidence of CHE among households with critically ill patients was $76.37 \%$ even after medical insurance reimbursement. Compared with studies in the general population on CHE using the same threshold, this proportion is much higher than the average incidence of $11.21 \%$ reported at national level between 2010 and $2016 .{ }^{36}$ The huge gap explicitly emphasised that households with critically ill patients and in rural areas seem associated with increased incidence of CHE. For instance, CHE for patients with cancer is consistently high, whether in Shanghai $(72.7 \%),{ }^{37}$ rural China $(96.1 \%),{ }^{38}$ India $(84 \%)^{39}$ or Iran $(67.9 \%) .{ }^{40}$

China introduced CII in 2012 to protect households from CHE and impoverishment, and implemented CII nationally by 2016. However, CII mainly covered hospitalisation expenses within existing medical insurance catalogues and required the current year's OOP amount to exceed a certain threshold. For instance, in Shandong Province, while the payment proportion and maximum payment limit of CII improved in the year of our study, the threshold also increased, ${ }^{41}$ and several coverage blind spots remain. First, patients whose accumulated expenses are high due to longterm or complex illnesses may still be ineligible for insurance if their annual OOP costs do not reach the CII reimbursement threshold. In our survey, $55.33 \%$ of the patients had been ill for more than 2 years, and the average length of illness was as high as 3.19 years. Second, some patients' medical expenditures or outpatient costs were not covered under the reimbursement policy. The average reimbursement rate was only $25.26 \%$ in our study, after considering the total costs inclusive of non-covered expenses. Finally, CII adopts a policy of tiered reimbursement. The higher the OOP expense, the higher the reimbursement rate. Therefore, we find that the reimbursement rate is positively associated with the occurrence of CHE in this study, because a high reimbursement rate implies a high OOP expense. Families with high medical expenses were still at high risk of impoverishment even after basic insurance and CII reimbursement.

It is worth noting that for households without CHE, the average reimbursement rate was as low as $11.93 \%$, 
Table 2 Single factors analysis of CHE among the study population

\begin{tabular}{|c|c|c|c|c|c|}
\hline Variables & & With CHE & Without CHE & Test statistic & $P$ value \\
\hline \multirow[t]{15}{*}{ Control variable } & Gender (N, \%) & & & $0.62^{*}$ & 0.431 \\
\hline & Male & $388(48.81 \%)$ & $113(45.93 \%)$ & & \\
\hline & Female & $407(51.19 \%)$ & $133(54.07 \%)$ & & \\
\hline & Marital status (N, \%) & & & $5.84^{*}$ & 0.016 \\
\hline & Married & $672(84.53 \%)$ & $223(90.65 \%)$ & & \\
\hline & Else & $123(15.47 \%)$ & $23(9.35 \%)$ & & \\
\hline & Dependency ratio (Median, IQR) & $0.50(0-1)$ & $0.33(0-0.6)$ & $-5.21 \dagger$ & $<0.001$ \\
\hline & Living conditions (N, \%) & & & $72.53^{*}$ & $<0.001$ \\
\hline & Live alone/empty nest & $533(67.04 \%)$ & $90(36.59 \%)$ & & \\
\hline & Else & $262(32.96 \%)$ & $156(63.41 \%)$ & & \\
\hline & Survey area $(\mathrm{N}, \%)$ & & & $5.13^{*}$ & 0.077 \\
\hline & $\mathrm{YT}$ & $274(34.47 \%)$ & $73(29.68 \%)$ & & \\
\hline & $\mathrm{HZ}$ & 249 (31.32\%) & $96(39.02 \%)$ & & \\
\hline & WF & $272(34.21 \%)$ & $77(31.30 \%)$ & & \\
\hline & Reimbursement rate (median, IQR) & $35.71(0-50)$ & $0(0-0)$ & $-9.99 \dagger$ & $<0.001$ \\
\hline \multirow[t]{3}{*}{ Human capital } & Education year (householder) (median, IQR) & $6(4-9)$ & $7(5-9)$ & $4.66 \dagger$ & $<0.001$ \\
\hline & Education year (patient) (median, IQR) & $6(2-8)$ & $6(3-9)$ & $3.31 \dagger$ & $<0.001$ \\
\hline & Health condition (patient) (median, IQR) & $0.73(0.52-0.86)$ & $0.85(0.65-0.94)$ & $6.32 \dagger$ & $<0.001$ \\
\hline Natural capital & Agricultural acreage (median, IQR) & $2(1-3.4)$ & $3(1.5-4)$ & $3.55 \dagger$ & $<0.001$ \\
\hline \multirow[t]{3}{*}{ Physical capital } & Housing floor area (median, IQR) & $80(60-100)$ & $80(61-120)$ & $4.99 \dagger$ & $<0.001$ \\
\hline & Amount of real estate (median, IQR) & $1(1-1)$ & $1(1-1)$ & $4.01 \dagger$ & $<0.001$ \\
\hline & Household-owned assets (mean \pm SD) & $0.38 \pm 0.17$ & $0.46 \pm 0.15$ & $7.13 \ddagger$ & $<0.001$ \\
\hline \multirow[t]{4}{*}{ Financial capital } & Household economic status (N, \%) & & & $55.09^{*}$ & $<0.001$ \\
\hline & Poor & $348(43.78 \%)$ & $65(26.42 \%)$ & & \\
\hline & Middle class & $367(46.16 \%)$ & $113(45.94 \%)$ & & \\
\hline & Wealthy & $80(10.06 \%)$ & $68(27.64 \%)$ & & \\
\hline \multirow[t]{6}{*}{ Social capital } & Number of constant contacts (median, IQR) & $4(2-6)$ & $5(3-9)$ & $4.90 \dagger$ & $<0.001$ \\
\hline & Borrowing capability (N, \%) & & & $35.73^{\star}$ & $<0.001$ \\
\hline & Not required & $185(23.27 \%)$ & $103(41.87 \%)$ & & \\
\hline & Capable & $498(62.39 \%)$ & $126(51.22 \%)$ & & \\
\hline & Uncertainly & $62(7.80 \%)$ & $10(4.06 \%)$ & & \\
\hline & Incapable & $52(6.54 \%)$ & $7(2.85 \%)$ & & \\
\hline
\end{tabular}

Bold values indicate these variables are statistically significant.

${ }^{*} \chi^{2}$ test.

†Wilcoxon test.

łt-test.

CHE, catastrophic health expenditure; HZ, Heze; WF, Weifang; YT, Yantai T.

and $77.24 \%$ of these households did not benefit from insurance at all. There are two potential explanations for this extremely low reimbursement rate. First, households without CHE usually face less severe chronic illnesses with OOP expenses lower than the deductible ceiling, which can also explain why we observed a positive association between the reimbursement rate and the incidence of CHE. Second, there are some forms of health-related spending, such as medicines for rare diseases or imported consumables, that cannot be covered by health insurance. ${ }^{11}$ In this case, patients may choose to reduce or refuse treatment, thus reducing health-related expenditures. ${ }^{42}$ Even among households with CHE, the average reimbursement rate was only $29.40 \%$. We should, therefore, also be aware of health spending that is not covered by insurance. Fortunately, however, China has begun to roll out private insurance programmes in combination with existing public health insurance that focus on these forms of medical expenses, such as Shandong's QiluBao launched in 2021. 
Table 3 Binary logistic regression analysis of associated factors of $\mathrm{CHE}$ among the study population

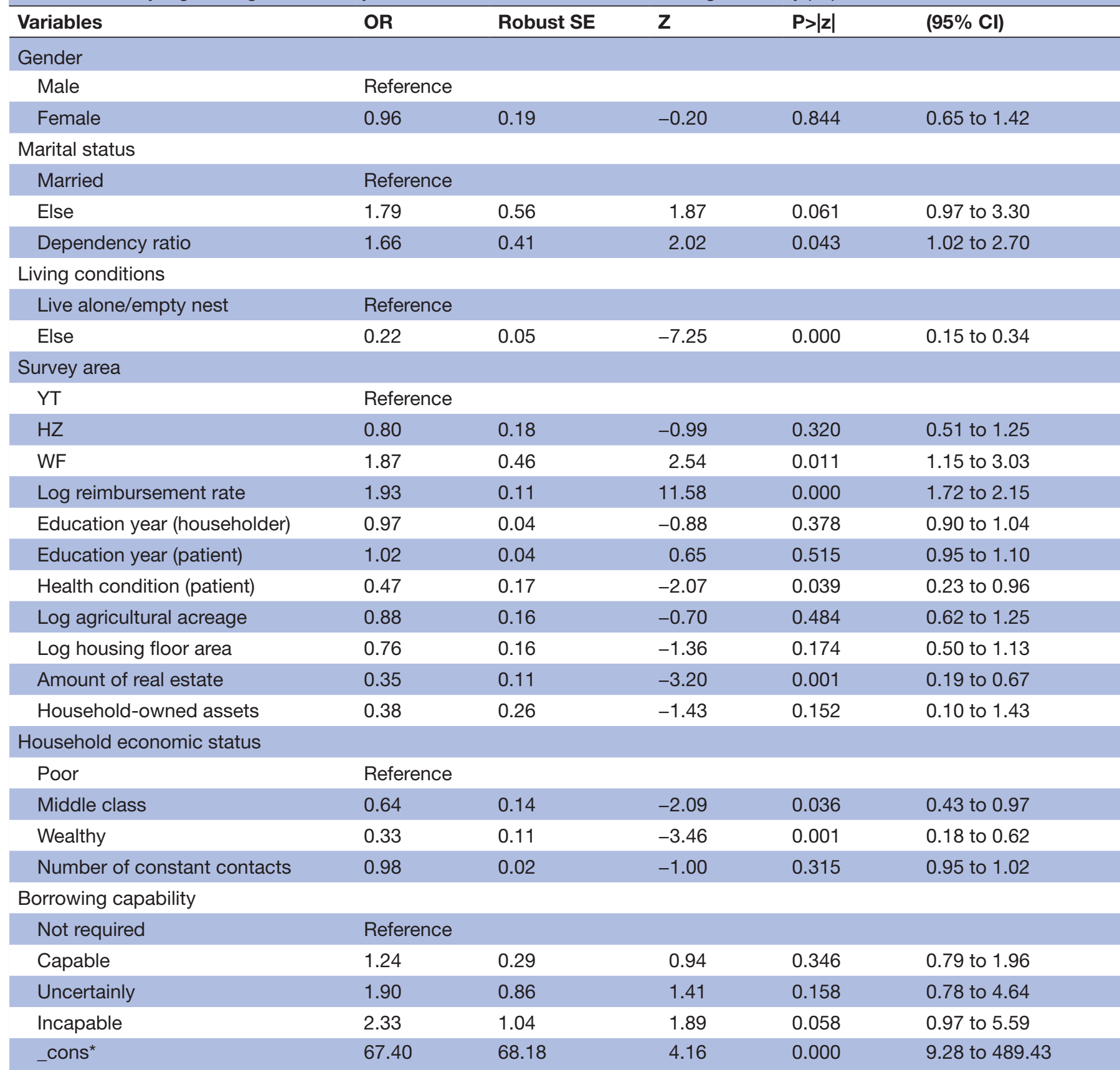

*_cons estimates baseline odds.

CHE, catastrophic health expenditure; HZ, Heze; WF, Weifang; YT, Yantai T.

This study explores the association between livelihood capital and financial risk mitigation in rural China. Our results suggest that human capital, physical capital and financial capital were associated with CHE, which provides us with possible pathways to $\mathrm{CHE}$ reduction besides health insurance.

With respect to human capital, self-reported health was inversely associated with CHE, a finding supported by some prior studies. ${ }^{23}$ In Grossman's health demand model, health is seen as an investment or commodity that can determine the timing and intensity of engagement in market activities. ${ }^{43}$ Personal health is a human investment that brings both value and utility to the individual. Many studies point out that health improvements can increase farmers' labour supply. ${ }^{44}$ Illness weakens patients both physically and mentally, which leads to a decline in the quality of human capital and reduces income. ${ }^{46}$

The key role of households' economic status in CHE was consistent with studies in other countries. ${ }^{24} 39$ In addition, increased real estate ownership was associated with reduced $\mathrm{CHE}$ at a significance level of 5\%. Our analysis suggests that physical and financial capital significantly 
influence the livelihood strategy of rural households. ${ }^{47}$ For instance, farmers with higher household income and better housing conditions are more likely to choose nonfarm business activities as their main occupation, while others are more likely to choose agricultural activities as their main occupation. We also find that an increase in physical and financial capital significantly reduces subjective poverty. ${ }^{48}{ }^{49}$ Improved housing conditions and economic status imply both material and psychological security.

Furthermore, some forms of livelihood capital appeared to reduce CHE but lacked statistical significance, including the education level of household members, family-owned agricultural acreage, a respondent's number of constant contacts and borrowing capabilities. According to previous studies, less-educated households are more prone to CHE. ${ }^{21}$ However, in this study, educational level was not statistically significant, a result that might be explained by lower average education levels. The average length of education was only 6.14 years for our respondents. Similarly, natural capital did not show a statistically significant association with CHE. The main source of income for Chinese farmers has shifted with industrialisation and urbanisation from agricultural to non-agricultural income ${ }^{50}$ and the role of land in farmers' income has diminished, ${ }^{51}$ which may reduce the impact of arable land on CHE. Thus, increasing nonagricultural income might help rural residents limit CHE. Extensive social networks did likewise appear to limit CHE, but not at a statistically significant level. It is possible that the quality of social networks is more important than the number of interactions individuals have in social networks. ${ }^{52}$

Additionally, patients with higher dependency ratios, patients living alone and patients with higher reimbursement rates showed a higher prevalence of CHE. The dependency ratio and living conditions might act as vulnerable context, and negatively affect the stability of livelihood capital. ${ }^{53}{ }^{54}$ More attention should be paid to households with fewer working members as well as patients who are living alone.

This study had several limitations. First, household incomes and healthcare expenditures were self-reported, which may cause recall biases. Second, the cross-sectional data may have variable omissions. Finally, we have only preliminarily explored the association between livelihood capital and CHE using the sustainable livelihoods framework. However, the relationships between livelihood assets, critical illness burdens and livelihood strategies may be further explored. We can improve the sustainable livelihood framework for rural households' burden of critical illnesses by constructing a comprehensive livelihood capital model and analysing mediating effects.

\section{CONCLUSION}

Human capital, physical capital and financial capital are all significantly associated with rural households' ability to mitigate or avoid CHE. These forms of capital are strongly associated with household health, real estate ownership, household assets, household economic status. Moreover, dependency ratios and living with others are also associated with mitigating CHE. To reduce the burden of disease on rural households, we should pay more attention to livelihood issues and establish a flexible and multidimensional compensation mechanism. As well as meeting the basic material needs of rural households, we should help them to strengthen education and help increase household income. Finally, a compensation mechanism for medical insurance better suited to rural households should be established.

Acknowledgements We thank the officials of health agencies, all participants and staffs at the study sites for making this study possible.

Contributors Study design: JL. Collection and assembly of data: JL, WF and FF. Data analysis and interpretation: XC. Manuscript writing: XC and JL. Final approval of manuscript: all authors. Accountable for all aspects of the work: all authors. Guarantor: XC.

Funding This work was supported by the Natural Science Foundation of China (NSFC), No.71673170, Natural Science Foundation of China (NSFC), No.7130313.

Competing interests None declared.

Patient consent for publication Not applicable.

Ethics approval The study was approved by the Ethics Committee of School of Public Health in Shandong University, P. R. China (20190101).

Provenance and peer review Not commissioned; externally peer reviewed.

Data availability statement Data are available on reasonable request. No additional data available. All data are presented in the article. The datasets used and analyzed during the current study are available from the corresponding author on reasonable request.

Supplemental material This content has been supplied by the author(s). It has not been vetted by BMJ Publishing Group Limited (BMJ) and may not have been peer-reviewed. Any opinions or recommendations discussed are solely those of the author(s) and are not endorsed by BMJ. BMJ disclaims all liability and responsibility arising from any reliance placed on the content. Where the content includes any translated material, BMJ does not warrant the accuracy and reliability of the translations (including but not limited to local regulations, clinical guidelines, terminology, drug names and drug dosages), and is not responsible for any error and/or omissions arising from translation and adaptation or otherwise.

Open access This is an open access article distributed in accordance with the Creative Commons Attribution Non Commercial (CC BY-NC 4.0) license, which permits others to distribute, remix, adapt, build upon this work non-commercially, and license their derivative works on different terms, provided the original work is properly cited, appropriate credit is given, any changes made indicated, and the use is non-commercial. See: http://creativecommons.org/licenses/by-nc/4.0/.

ORCID iD

Xin Che http://orcid.org/0000-0002-9178-938X

\section{REFERENCES}

1 China TSCIOotPsRo. Press conference of "three one batch" action plan of health poverty alleviation project, 2017. Available: http://www. scio.gov.cn/video/33836/Document/1549589/1549589.htm

2 Gajic O, Ahmad SR, Wilson ME, et al. Outcomes of critical illness. Curr Opin Crit Care 2018;24:394-400.

3 Khandelwal N, May P, Curtis JR. Financial stress after critical illness: an unintended consequence of high-intensity care. Intensive Care Med 2020;46:107-9.

4 Strauss J, Thomas D. Health, nutrition, and economic development. Journal of Economic Literature 1998;36:766-817.

5 Oshio T, Kobayashi M. Income inequality, area-level poverty, perceived aversion to inequality, and self-rated health in Japan. Soc Sci Med 2009;69:317-26. 
6 Zafar SY, Peppercorn JM, Schrag D, et al. The financial toxicity of cancer treatment: a pilot study assessing out-of-pocket expenses and the insured cancer patient's experience. Oncologist 2013:18:381-90.

7 Carrera PM, Kantarjian HM, Blinder VS. The financial burden and distress of patients with cancer: understanding and stepping-up action on the financial toxicity of cancer treatment. CA Cancer J Clin 2018;68:153-65.

8 Kruk ME, Goldmann E, Galea S. Borrowing and selling to pay for health care in low- and middle-income countries. Health Aff 2009;28:1056-66.

9 Mclntyre D, Thiede M, Dahlgren G, et al. What are the economic consequences for households of illness and of paying for health care in low- and middle-income country contexts? Soc Sci Med 2006;62:858-65.

10 Regional Committee for the Western Pacific. Health financing strategy for the Asia Pacific Region (2010-2015)(Resolution), 2009. Available: https://apps.who.int/iris/handle/10665/249459

11 Zhao S-W, Zhang X-Y, Dai W, et al. Effect of the catastrophic medical insurance on household catastrophic health expenditure: evidence from China. Gac Sanit 2020;34:370-6.

12 Bray F, Ferlay J, Soerjomataram I, et al. Global cancer statistics 2018: GLOBOCAN estimates of incidence and mortality worldwide for 36 cancers in 185 countries. CA Cancer J Clin 2018;68:394-424.

13 Zheng RS, Sun KX, Zhang SW, et al. [Report of cancer epidemiology in China, 2015]. Zhonghua Zhong Liu Za Zhi 2019;41:19-28.

14 Guy GP, Ekwueme DU, Yabroff KR, et al. Economic burden of cancer survivorship among adults in the United States. J Clin Oncol 2013;31:3749-57.

15 Altice CK, Banegas MP, Tucker-Seeley RD, et al. Financial Hardships experienced by cancer survivors: a systematic review. J Natl Cancer Inst 2017;109. doi:10.1093/jnci/djw205. [Epub ahead of print: 2010 2016].

16 Landwehr MS, Watson SE, Macpherson CF, et al. The cost of cancer: a retrospective analysis of the financial impact of cancer on young adults. Cancer Med 2016;5:863-70.

17 Shankaran V, Jolly S, Blough D, et al. Risk factors for financial hardship in patients receiving adjuvant chemotherapy for colon cancer: a population-based exploratory analysis. J Clin Oncol 2012;30:1608-14.

18 DFID. Sustainable livelihoods guidance sheets, 1999. Available: https://www.livelihoodscentre.org/-/sustainable-livelihoodsguidance-sheets

19 Scoones I. Sustainable rural Livelihoods: a framework for analysis. IDS Working Paper No 1998;72.

20 Lowe L, Schilderman T. The impact of policies institutions and processes in urban upgrading 2001.

21 Li Y, Wu Q, Xu L, et al. Factors affecting catastrophic health expenditure and impoverishment from medical expenses in China: policy implications of universal health insurance. Bull World Health Organ 2012;90:664-71.

22 Özgen Narcı H, Şahin İsmet, Yıldııım HH. Financial catastrophe and poverty impacts of out-of-pocket health payments in turkey. Eur $\mathrm{J}$ Health Econ 2015;16:255-70.

23 Zhong Z, Wei H, Yang L, et al. Catastrophic health expenditure: A comparative analysis of smoking and non-smoking households in China. PLoS One 2020;15:e0233749.

24 Sui M, Zeng X, Tan WJ, et al. Catastrophic health expenditures of households living with pediatric leukemia in China. Cancer Med 2020;9:6802-12.

25 Onwujekwe O, Hanson K, Uzochukwu B. Examining inequities in incidence of catastrophic health expenditures on different healthcare services and health facilities in Nigeria. PLoS One 2012;7:e40811.

26 Buigut S, Ettarh R, Amendah DD. Catastrophic health expenditure and its determinants in Kenya slum communities. Int $J$ Equity Health 2015;14:46.

27 Chen W, Zheng R, Baade PD, et al. Cancer statistics in China, 2015. CA Cancer J Clin 2016;66:115-32.

28 Pandey A, Ploubidis GB, Clarke L, et al. Trends in catastrophic health expenditure in India: 1993 to 2014. Bull World Health Organ 2018;96:18-28.

29 Reid-Arndt SA, Cox CR. Does rurality affect quality of life following treatment for breast cancer? J Rural Health 2010;26:402-5.

30 Shandong Provincial Bureau of Statistics. Shandong statistical Yearbook China statistical publishing house, 2020. Available: http:// tjj.shandong.gov.cn/tjnj/nj2020/zk/indexch.htm

$31 \mathrm{Li} \mathrm{H}$, Jiang L. Catastrophic medical insurance in China. The Lancet 2017;390:1724-5.
32 Hu L-ping, Bao X-lei, Zhou S-guo, et al. Estimation of sample size and testing power (Part 1). Zhong Xi Yi Jie He Xue Bao 2011;9:1070-4

33 Shackman G. Sample size and design effect Albany chapter of American statistical association, 2001. Available: https://www.alnap. org/help-library/sample-size-and-design-effect

34 Wagstaff $A$, Lindelow M, MJJoHE L. Can insurance increase financial risk? the curious case of health insurance in China. $J$ Health Econ 2008;27:990-1005.

$35 \mathrm{Xu} \mathrm{K}$. Distribution of health payments and catastrophic expenditures methodology, 2005. Available: https://apps.who.int/iris/handle/ $10665 / 69030$

36 Ma X, Wang Z, Liu X. Progress on catastrophic health expenditure in China: evidence from China family panel studies (CFPS) 2010 to 2016. Int J Environ Res Public Health 2019;16:4775.

37 Chen JE, Lou VW, Jian H, et al. Objective and subjective financial burden and its associations with health-related quality of life among lung cancer patients. Support Care Cancer 2018;26:1265-72.

38 Leng A, Jing J, Nicholas S, et al. Catastrophic health expenditure of cancer patients at the end-of-life: a retrospective observational study in China. BMC Palliat Care 2019;18:43.

39 Jain M, Mukherjee K. Economic burden of breast cancer to the households in Punjab, India. International Journal of Medicine and Public Health 2016;6:13.

40 Kavosi Z, Delavari H, Keshtkaran A. Catastrophic health expenditures and coping strategies in households with cancer patients in Shiraz Namazi Hospital. Middle East Journal of Cancer 2014;5:13-22.

41 Province HRaSSDoS, Finance SPDo, Commission SphaFP. Notice on further improving the system of serious illness insurance for residents, 2018. Available: http://hrss.shandong.gov.cn/articles/ ch06567/202012/45e4b838-391a-4e86-84c6-23a1980d322e.shtml

$42 \mathrm{Li} \mathrm{Y,} \mathrm{Wu} \mathrm{Q,} \mathrm{Liu} \mathrm{C,} \mathrm{et} \mathrm{al.} \mathrm{Catastrophic} \mathrm{health} \mathrm{expenditure} \mathrm{and}$ rural household impoverishment in China: what role does the new cooperative health insurance scheme play? PLoS One 2014:9:e93253.

43 Grossman M. The demand for health: a theoretical and empirical investigation. New York: Columbia University Press for the National Bureau of Economic Research, 1972.

44 Fink G, Masiye F. Health and agricultural productivity: evidence from Zambia. J Health Econ 2015;42:151-64.

45 Li Q, Lei X, Zhao Y. The effect of health on the labor supply of midaged and older Chinese. China Economic Quarterly 2014;13:917-38.

46 Muka T, Imo D, Jaspers L, et al. The global impact of noncommunicable diseases on healthcare spending and national income: a systematic review. Eur J Epidemiol 2015;30:251-77.

47 Wu L, Jin L. Influence of eco-compensation on peasant households' livelihood in poverty-stricken regions in Guizhou Province. Journal of Arid Land Resources and Environment 2018;32:1-7.

48 Chan SM, Wong H. Impact of income, deprivation and social exclusion on subjective poverty: a structural equation model of multidimensional poverty in Hong Kong. Social Indicators Research 2020;152:971-90.

49 Yang $\mathrm{Q}$, Chen $\mathrm{C}$, Zhang $\mathrm{K}$, et al. Housing property rights and the Urban residents' happiness: based on Empirical research of CGSS2003 and CGSS2013. Northwest Population Journal 2018;39:11-20+29.

50 Liu J, Lu Y, Xu Q, et al. Public health insurance, non-farm labor supply, and farmers' income: evidence from new rural cooperative medical scheme. Int J Environ Res Public Health 2019;16:4865.

51 Luo Y, Fan L. The role of land in growth of farmers' income: protection or Obstacle? Economic Research Journal 2015;50:146-61.

52 Lu S, Wu Y, Mao Z, et al. Association of formal and informal social support with health-related quality of life among Chinese rural elders. Int J Environ Res Public Health 2020;17:1351.

53 Xie H, Lin G, Fang P. Impact of family burden on stability of nonagricultural employment of rural labor-based on analysis of CFPS from 2014 to 2016. Jiangsu Agricultural Sciences 2020;48:42-6.

54 Yue Z, Tian J. Urban empty-nest elderly under the impact of epidemic situation:livelihood risk and its reconstruction. Xinjiang State Farms Economy 2020;08:54-60.

55 Luo N, Liu G, Li M, et al. Estimating an EQ-5D-5L value set for China. Value in Health 2017;20:662-9.

56 Yang Y, Zhao F. A Survey of farmers' livelihood capital in the framework of the sustainable livelihood approach:a case study of the reservoir zone of the South-to-North Water transfer (Middle Line) project. Issues in Agricultural Economy 2009:58-65+111. 